\title{
DEVELOPMENT OF GASIFICATION/COMBUSTION CHARACTERISTICS AT THERMO- CHEMICAL CONVERSION OF BIOMASS MIXTURES
}

\author{
Inesa Barmina ${ }^{1}$, Raimonds Valdmanis ${ }^{1}$, Maija Zake ${ }^{1}$, Liva Ozola ${ }^{2}$, Uldis Strautins ${ }^{2}$ \\ ${ }^{1}$ Institute of Physics, University of Latvia; \\ ${ }^{2}$ Institute of Mathematics and Computer Science, University of Latvia \\ mzfi@sal.lv; uldis.strautins@lu.lv
}

\begin{abstract}
To promote more effective utilization of wheat straw for cleaner heat energy production with reduced greenhouse carbon and polluting emissions, experimental study and mathematical modelling of the processes of wheat straw co-combustion with wood and peat pellets are carried out with the aim to assess the impact of the mixture composition on the development of the main gasification/combustion characteristics and heat energy production. The processes of thermal decomposition of wheat straw mixtures and combustion of volatiles were studied experimentally by varying the mass load of wheat straw pellets in the mixtures. The development of the main gasification/combustion characteristics was studied experimentally using a batch-size pilot setup with a heat output up to $2 \mathrm{~kW}$, which combines a biomass gasifier and a combustor. The results of the experimental study and mathematical modelling suggest that creating a mixture of fuels, which have different elemental compositions and heating values of the components, makes it possible to control the thermal decomposition of wheat straw by varying the mass flow of volatiles entering the combustor and so improving the combustion conditions in the flame reaction zone, which results in faster ignition with more complete combustion of the volatile compounds and in cleaner heat energy production.
\end{abstract}

Keywords: gasification, combustion, wheat straw mixtures.

\section{Introduction}

Biomass pellets (wood, wheat straw, rape straw, and peat) as fuels are of great interest for district heating because they can contribute to greenhouse gas emission reductions and provide a more efficient use of local energy resources. The test experiments of their applicability for the heat energy production have shown that wood pellets are most suitable as a fuel in boilers without any operational problems [1]. Problems can arise if wheat straw or peat pellets are used as a fuel for the heat production, because they have a higher ash and nitrogen content and a higher release of hazardous emissions (PAHs, $\mathrm{CO}, \mathrm{HCl}$ ) during their thermal decomposition, with serious impact on the boiler operation, human health and on the environment $[2 ; 3]$. Actually, the operational and ash-related problems of boilers can be partially reduced by the co-combustion of such mixtures as straw with wood, coal or peat $[4 ; 5]$. Co-combustion of different solid fuels allows to improve the boiler operation, to control the slagging and fouling tendency, ash deposition and bed agglomeration as well as the formation of polluting emissions. The results of advanced studies of these processes [4-6] show that the development of these processes is highly influenced by the variation of the chemical and elemental composition of biomass pellets to be mixed and depends on the mass load of fuels in the mixture. In fact, it is very difficult to predict and extrapolate the results of experimental studies which might be obtained for a specific fuel mixture to biomass mixtures with a different elemental and chemical composition of the components. Therefore, a more fundamental research with mathematical modelling and numerical analysis of the processes is required to understand the main mechanisms determining the development of the gasification/combustion characteristics of biomass mixtures, slagging, fouling, ash deposition and bed agglomeration as well as of the development of the main processes that are responsible for the formation of the composition of polluting emissions [6]. The reported study is mainly concerned with detailed investigations of the gasification/combustion characteristics and of the composition of the products by co-combusting wheat straw pellets with wood and peat pellets and by combining the experimental results with those of mathematical modelling and numerical analysis of the processes in order to assess the main factors which determine the development of thermo-chemical conversion of these mixtures, the heat output and the composition of emissions.

\section{Mathematical modeling and numerical results}

We focus on the combustion characteristics of the biogas, with $\mathrm{CO}, \mathrm{H}_{2}$ being the main combustible volatiles. The experimental series of this study has demonstrated that the rate of formation of the volatile gases in the gasifier depends on the stage of the gasification process as well 
as on the composition of the biomass. The production of heat and emissions in the burner section is controlled by the composition and mass flowrate of the volatile gases. We developed a model in the ANSYS Fluent CFD environment.

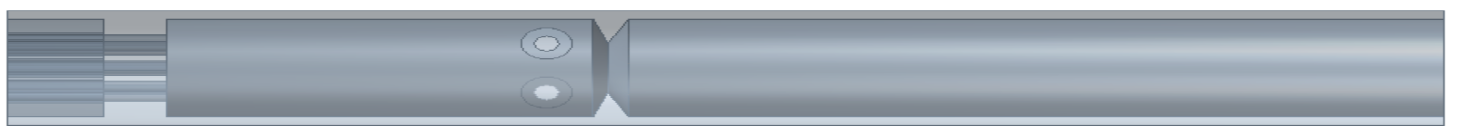

Fig. 1. Geometry of the gasifier and combustor. Primary air inlets are depicted by circles

The combustor is modelled as a cylinder of the length $\sim 600 \mathrm{~mm}$, radius $30 \mathrm{~mm}$, with the bottleneck imitating the burner nozzle with the radius $15 \mathrm{~mm}$. Two inlets for primary air are added to generate a swirling flow. The gasifier is presented as a device for mixing $\mathrm{CO}, \mathrm{H}_{2}$ at the bottom of the geometry, cf. Fig. 1

Two exothermic reactions are used for combustion of $\mathrm{H}_{2}$ and $\mathrm{CO}$. The models applied are energy equations with radiative heat transfer ( $\mathrm{P} 1$ model), the $\mathrm{k}-\varepsilon$ turbulence model with the constants $C_{\mu}=0.0845, C_{1 \varepsilon}=1.42, C_{2 \varepsilon}=1.68$, the wall Prandtl number $=0.85$; for both species a non-premixed combustion model, boundary conditions accounting for the heat transfer to the walls and the backflow temperature at the outlet are applied. The temperature for the primary air is set to $295 \mathrm{~K}$ and to $650 \mathrm{~K}$ for the biogas. The mass flowrate of the primary air is $10^{-3} \mathrm{~kg} \cdot \mathrm{s}^{-1}$, and the mass flowrate of the biogas was varied in the range $(1-6) \cdot 10^{-4} \mathrm{~kg} \cdot \mathrm{s}^{-1}$.

A non-stationary simulation is performed until a quasi-stationary state is obtained. The sample streamline plots are shown in Fig. 2-3.

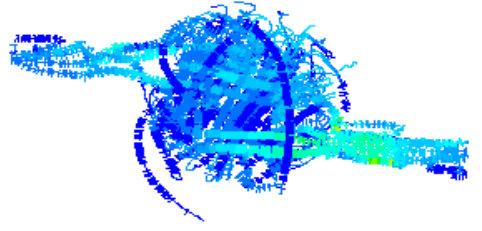

Fig. 2. Streamlines for a gas mixture with the $\mathrm{H}_{2}$ :CO volume fraction $2: 3$ (top view)

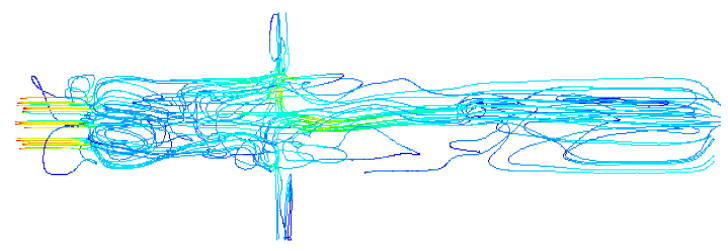

Fig. 3. Streamlines for a gas mixture with the $\mathrm{H}_{2}$ : CO volume fraction 2:3 (side view). Color signifies absolute velocity

Flame temperatures as predicted by the simulation are given in Fig. 4. The simulations offer a detailed insight into the combustion process, giving the temperature and velocity distributions in the flame. Further studies are required to couple the gasification stage to the combustion stage.

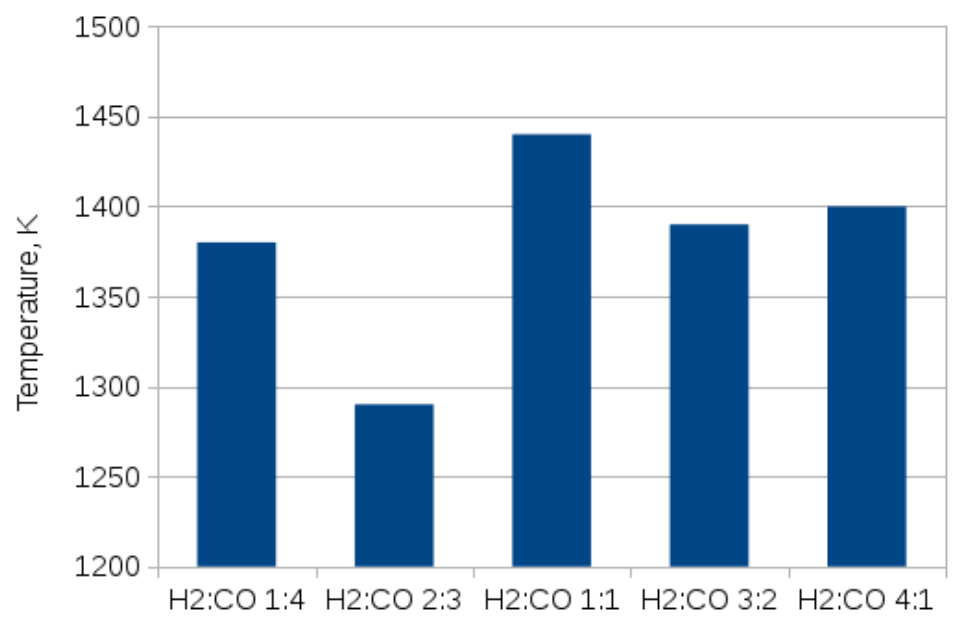

Fig. 4. Flame temperatures for specified ratios of the volume fraction of hydrogen and carbon monoxide in the fuel mixture 


\section{Experimental research}

To study the effects of the wheat straw co-gasification/co-combustion with wood or peat pellets, a batch-size pilot device was used combining a biomass gasifier and a combustor [7] of inner diameter $D=60 \mathrm{~mm}$ and of total length up to $600 \mathrm{~mm}$. The gasifier was filled up with a mixture of biomass pellets. The total mass of a mixture, which is supplied into the gasifier, depends on the density of the components and on the mixture composition and it was varied in the range from $m=160 \mathrm{~g}$ to $m=\mathrm{g}$. The gasifier is separated from the combustor by the conical nozzle of inner diameter $40 \mathrm{~mm}$. The thermal decomposition (gasification) of biomass pellets (straw, wood, peat and their mixtures) was initiated by injecting a propane flame flow directly into the upper part of the biomass layer with the given average heat input $1 \mathrm{~kW}$. The additional heat supply was switched off at $t \approx 360$ s providing the co-combustion of straw with wood pellets and at $t \approx 700$ s providing the co-combustion of straw with peat pellets. The primary air was supplied below the layer of biomass pellets at the average rate $201 \cdot \mathrm{min}^{-1}$ to sustain the thermal decomposition of the main biomass components (hemicellulose, cellulose and lignin). The thermal decomposition of the biomass pellets developed under the fuel-rich conditions $(\alpha<0.5)$ and resulted in the formation of the axial flow of the combustible volatiles (CO, $\mathrm{H}_{2}$ ) and $\mathrm{CO}_{2}$ products entering the combustor. The secondary swirling air was supplied below the inlet nozzle of the combustor, close above the propane flame injection nozzle, at the average rate $301 \cdot \mathrm{min}^{-1}$. The secondary air was used to provide enhanced mixing of the axial flow of the combustible volatiles with the air swirl and to support the self-sustaining combustion of the volatiles $\left(\mathrm{CO}, \mathrm{H}_{2}\right)$ downstream the water-cooled combustor. The combustion of the volatiles develops at the air excess ratio $\alpha \approx 1.6-2$ in the flame reaction zone and at the average value of the inlet air flow swirl number $S \approx 0.3-0.45$ which was estimated from the measurements of the average values of the axial $\left(u_{z}\right)$ and tangential $\left(u_{\varphi}\right)$ flow velocities $\left(S \approx 2 / 3 \cdot u_{\varphi} / u_{z}\right)$ close above the inlet nozzle $(L / D=1.3)$ of the combustor.

The experimental study of the gasification/combustion characteristics of biomass mixtures includes complex measurements of the flow velocity components using a Pitot tube; the flame temperature was measured by $\mathrm{Pt} / \mathrm{Pt}-\mathrm{Rh}$ thermocouples and the composition of the products was measured by gas sampling probes. The calorimetric measurements of the cooling water flow were made to assess the influence of the mixture thermal decomposition on the heat output of the device. All measurements were made along with the online data registration of the main combustion characteristics [7].

\section{Results and discussion}

This study aims to assess the influence of wheat straw additives on the development of the main combustion characteristics by co-firing wheat straw with wood and peat pellets and to reduce the negative effects of straw on the heat output and composition of the emission. The kinetics of the gasification/combustion characteristics at thermo-chemical conversion of the wood mixtures first of all depends on the mixture composition and on the mass load of the components in the mixture. In addition, the kinetics of the combustion dynamics is highly influenced by the elemental composition of the mixture components. The elemental compositions of the components for the biomass samples, which are used in this study, significantly differ and are summarized in Table 1.

Elemental composition and heating values of biomass pellets

Table 1

\begin{tabular}{|c|c|c|c|c|c|c|c|c|}
\hline Biomass type & $\mathrm{C}, \%$ & H, \% & $0, \%$ & $\mathrm{~N}, \%$ & Moisture, \% & Ash, \% & HHV, MJ・ $\mathbf{k g}^{-1}$ & LHV MJ· $\mathbf{k g}^{-1}$ \\
\hline wood & 45.52 & 4.86 & 41.81 & 0.129 & 7.4 & 0.277 & 18 & 16.67 \\
\hline wheat straw & 42.75 & 5.55 & 39.67 & 0.84 & 6.5 & 4.67 & 17.05 & 15.94 \\
\hline peat & 49.67 & 5.33 & 34.7 & 1.069 & 6.2 & 2.81 & 19.58 & 18.13 \\
\hline
\end{tabular}

Furthermore, the combustion characteristics during the co-firing of wheat straw with wood and peat pellets are influenced by the chemical composition of the pellets, i.e. the content of hemicelluloses (HC), cellulose and lignin in the biomass. The highest content of $\mathrm{HC}$ and cellulose is found in woody biomass, the highest content of lignin in peat pellets, whereas the lowest content of lignin is found in wheat straw pellets [8]. In addition, the wheat straw pellets have a relatively high content (up to $28 \%$ ) of residual components, e.g., ash and low-molecular weight carbohydrates and 
waxes that are the main factors limiting the use of straw for the heat energy production [8]. The difference between the elemental and chemical compositions of biomass pellets determines the variations of the ash yields (Table 1) and the release of volatile matter (VM) at thermo-chemical conversion of biomass pellets. The volatile matter content $(\mathrm{db})$ is larger for wood pellets $(77.5 \%)$, reduces to $67.2 \%$ for wheat straw and to $57.8 \%$ for peat [9], with direct influence on the kinetics of the gasification/combustion characteristics by varying the mixture composition and the mass load of straw in the mixture.

The thermo-chemical conversion of the mixtures in this study develops as a multi-stage process and can be characterized by the formation of the primary stage of mixture drying, heating and thermal decomposition of the main components ( $\mathrm{HC}$, cellulose and lignin) which occur if the biomass temperature in the gasifier approaches $T \approx 500 \mathrm{~K}$. The pellet thermal decomposition results in the formation of the axial flow of the combustible volatiles $\left(\mathrm{CO}, \mathrm{H}_{2}\right)$ above the biomass layer which rapidly mix with the reverse tangential flow of the secondary air promoting the ignition of the volatiles followed by the development of the flaming combustion and after-flame smouldering stages downstream the weakly swirled flame flow $(S \approx 0.3-0.4)$. Increasing the mass load of wheat straw pellets in the mixture leads to a delay of the ignition and flaming combustion of the volatiles $\left(\mathrm{CO}, \mathrm{H}_{2}\right)$, whereas it increases the peak values of the flame temperature and heat output from the flame reaction zone with the correlating increase of the $\mathrm{CO}_{2}$ volume fraction in the products (Fig. 5, a-c).
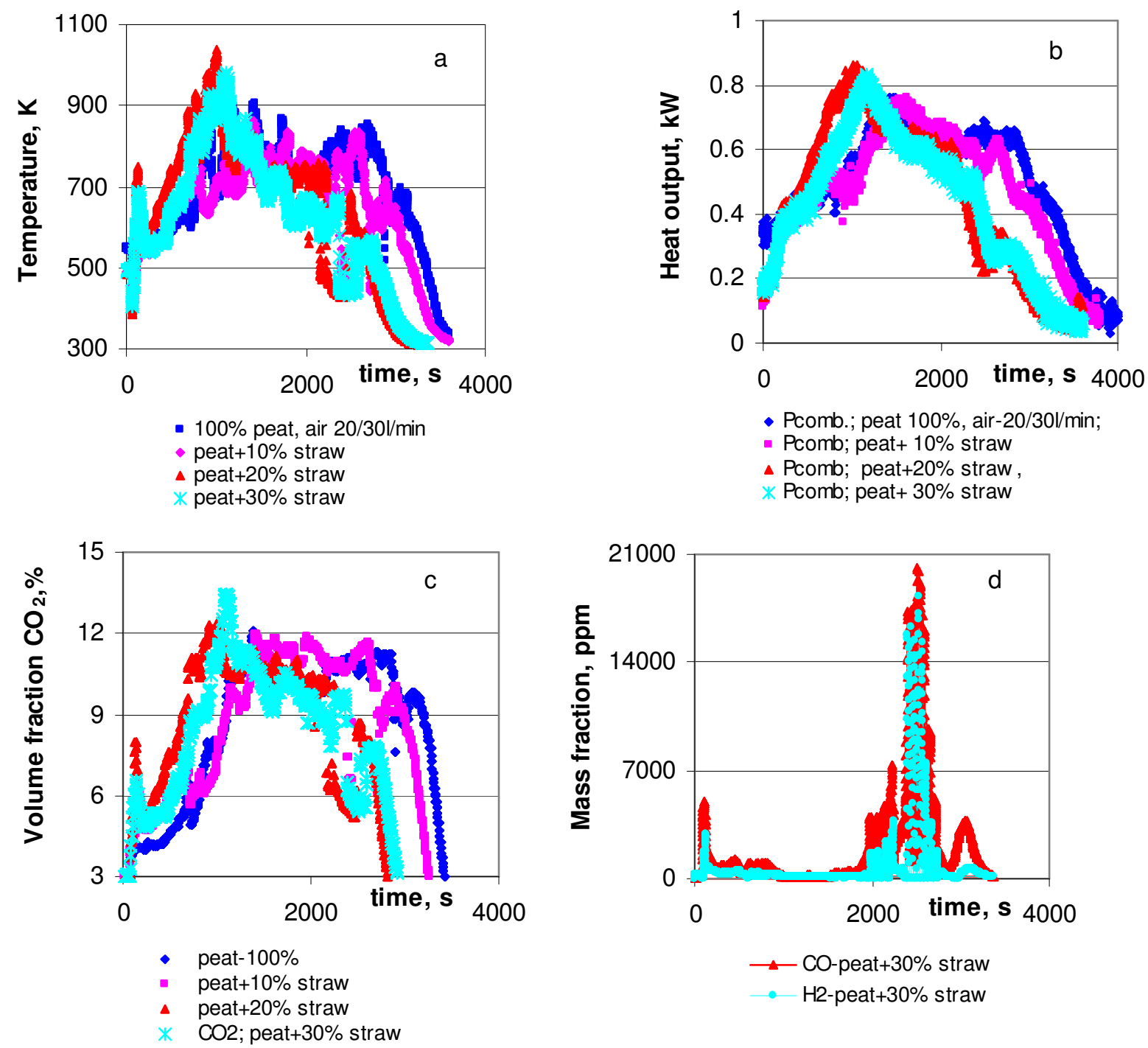

Fig. 5. Effect of the straw co-firing with wood pellets on the kinetics of the combustion characteristics at thermo-chemical conversion of the mixture: $a$ - flame temperature; $b$ - heat output; $\mathrm{c}-\mathrm{CO}_{2}$ volume fraction; $\mathrm{d}$ - mass fraction of combustible volatiles 
During the after-flame smouldering stage, the increase of the mass load of straw in the mixture leads to a reduction of the flame temperature with a correlating decrease of the heat output and $\mathrm{CO}_{2}$ volume fraction in the products. During this stage, the air excess ratio $(\alpha)$ in the products increased from $\alpha \approx 1.7-1.8$ for the flaming combustion stage up to 2.4-2.6 for the after-flame smouldering stage. Moreover, the decrease of the flame temperature and the development of the lean combustion conditions promoted the formation of combustion instability at the end stage of the thermo-chemical conversion of the mixture by exciting the low-frequency oscillations of the mass fraction of the unburned volatiles in the products (Fig. 5- d) as well as of the flame temperature, heat output and $\mathrm{CO}_{2}$ volume fraction in the products.

The enhanced ignition and flaming combustion of the volatiles were observed at the thermochemical conversion of wheat straw pellets mixed with peat pellets which have higher content of lignin with the reduced content of $\mathrm{HC}$ and celluloses. When increasing the mass load of straw in the mixture, the higher content of $\mathrm{HC}$ and celluloses in the straw pellets provided the faster ignition and flaming combustion of the volatiles along with the most pronounced increase of the flame temperature and heat output up to the peak values (Fig. 2, a-b), with a mass load of straw pellets being about $20 \%$. By analogy with the mixture of straw with wood pellets, the transition to the after-flame smoldering stage resulted in the decrease of the flame temperature, heat output of the device and $\mathrm{CO}_{2}$ volume fraction in the products along with the development of combustion instability (Fig. 6, a-d).
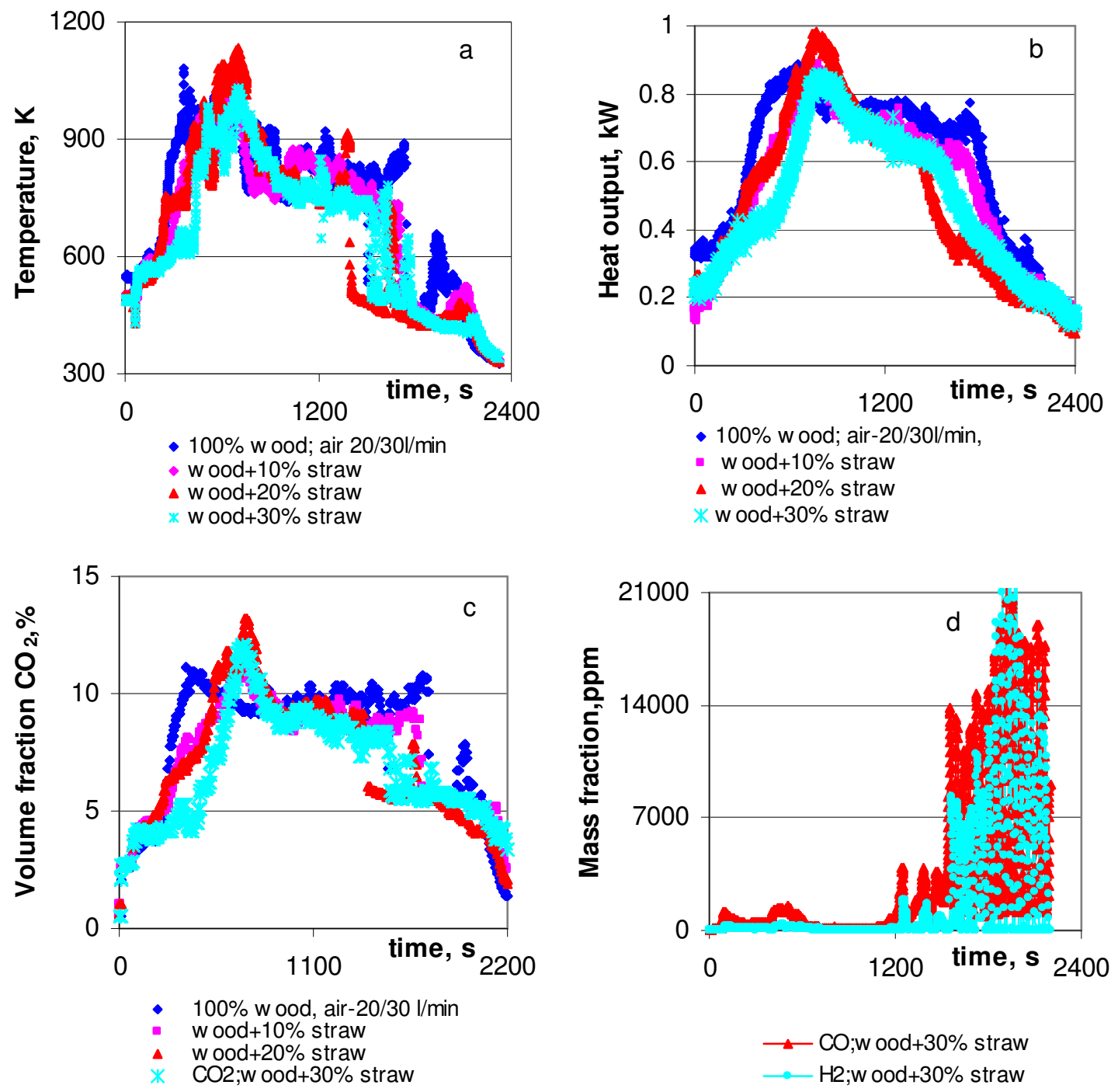

Fig. 6. Effect of the straw co-firing with peat pellets on the kinetics of the main combustion characteristics at thermo-chemical conversion of the mixture: $a$ - flame temperature; $b$ - heat output; $\mathrm{c}-\mathrm{CO}_{2}$ volume fraction; $\mathrm{d}$ - mass fraction of combustible volatiles 


\section{Conclusions}

1. A complex experimental study of the main gasification/combustion characteristics at thermo chemical conversion of straw mixtures with wood and with peat pellets was carried out and compared to assess the suitability of the straw co-firing for clean heat energy production.

2. During the co-firing of straw with wood pellets, the increase of the mass load of straw in the mixture results in ignition delay, whereas it provides the increase of the peak values of the flame temperature, heat output and volume fraction of $\mathrm{CO}_{2}$ in the products during the flaming combustion of the volatiles with the optimal mass load of straw about $20 \%$.

3. During the co-firing of straw with peat pellets, the increase of the mass load of straw in the mixture results in enhanced ignition and flaming combustion of the mixture with the optimal mass load of straw in the mixture about $20 \%$.

4. The negative effect of the straw co-firing with wood and with peat is observed during the after-flame smouldering stage, when the increase of the mass load of straw in the mixtures results in a decrease of the flame temperature and heat output with a correlating increase of the air excess ratio, which has led to the development of combustion instability.

\section{Acknowledgments}

The authors would like to acknowledge financial support from the European Regional Development Funding of project No. 1.1.1.1./16/A/004.

\section{References}

1. Andreasen P., Larsen M. Straw pellets as fuel in biomass combustion units, Proceedings of $9^{\text {th }}$ European Bioenergy Conference in Copenhagen, 1996, pp. 1-6.

2. Kallio M. "Best practice examples" for the combustion of alternative and mixed biomass pellets. Report of the IEE/09/758/S12.558286 - Mix BioPells WP3/D3.3, supported by the European Commission under EIE programme, 29 p. [online][11.12.2017] Available at: https://ec.europa.eu/energy/intelligent/projects/sites/ieeprojects/files/projects/documents/mixbiopells_best_practices_combustion_en.pdf

3. Nordgrem D., Hedman H., Padban N., Boström D., Öhman M. Ash transformations in pulverized fuel co-combustion of straw and woody biomass. Fuel Processing Technology, vol. 105, 2013, pp. 52-58.

4. Hupa M., Interaction of fuels in co-firing in FBC. Fuel, vol. 84, issue 10, 2005, pp. 1312-1319.

5. Shao Y., Wang J., Preto F., Zhu J, Xu Ch. Ash deposition in biomass combustion or co-firing for power/heat generation. Energies, vol. 5, 2012, pp. 5171-5189.

6. Kalis H., Barmina I., Zake M., Koliskins A., Mathematical modelling and experimental study of electrodynamic control of swirling flame flows. Engineering for Rural Development, 2016, pp. 134-141, ISSN 1691-3043. http://www.scopus.com/record/display.uri?eid=2-s2.084976555819\&origin=inward

7. Abricka M., Barmina I., Valdmanis R., Zake M., Kalis H. Experimental and numerical studies on integrated gasification and combustion of biomass. Chemical Engineering Transactions, vol. 50 (2016), p.127-132. [online][11.12.2017] Available at: http://www.aidic.it/cet/16/50/022.pdf ISBN 9788895608419.

8. Olsson M. Wheat straw and peat for fuel pellets - organic compounds from combustion. Biomass and Bioenergy, vol. 30, 2006, pp. 555-564.

9. Vassilev S.V., Baxter D., Andersen L.K., Vassileva Ch. G. An overview of the chemical composition of biomass. Fuel, vol. 89, 2010, pp. 913-933. 